\title{
The use of negative pressure wave treatment in athlete recovery
}

\author{
A Jansen van Rensburg1, MSc, D C Janse van Rensburg1, MD, \\ H E van Buuren ${ }^{2}$, MSc (Exerc Physiol), C C Grant ${ }^{1}$, PhD, L \\ Fletcher ${ }^{3}, \mathrm{PhD}$
}

${ }^{1}$ Section Sports Medicine, Faculty of Health Science, University of Pretoria, Pretoria, South Africa

2Institute for Sports Research, University of Pretoria, Pretoria, South Africa ${ }^{3}$ Department of Statistics, Faculty of Natural \& Agricultural Sciences, University of Pretoria, Pretoria, South Africa

Corresponding author: A Jansen van Rensburg

(audrey.jansenvanrensburg@up.ac.za)

Background: Athletes need to recover fully to maximise performance in competitive sport. Athletes who replenish more quickly and more efficiently are able to train harder and more intensely. Elite athletes subjectively report positive results using lower body negative pressure (LBNP) treatment as an alternate method for rapid recovery, restoring and improving their impaired physical state. Objective data on the efficacy are lacking.

Objectives: To investigate the effect of intermittent vacuum therapy on accelerating acute recovery following an athlete's normal daily training schedule of strenuous exercise. Objective measurements of biological markers of muscular fatigue were used to assess recovery.

Methods: Twenty-two male cricket players in a randomised cross-over study were divided into a treatment and control group respectively. Following a one-hour high-intensity gym session, the treatment group received three 30-minute LBNP exposure sessions over three consecutive days $(0,24$ and 48 hours). Blood lactate and creatine kinase biomarkers were collected to measure the recovery process. After 14 days groups were crossed over and the trial repeated.

Results: Heart rate and blood pressure decreased noticeably during treatment, reverting to baseline levels after treatment. Lactate concentrations decreased in both groups after exercise termination; significantly more in the treatment $(0.57 \pm 0.23$ $\mathrm{mmol} / \mathrm{l})$ than control group $(0.78 \pm 0.22 \mathrm{mmol} / \mathrm{l}), \mathrm{p}<0.001)$. Creatine kinase (CK) was similar in both groups. Athletes' subjective assessments of recovery rated moderately high.

Conclusion: LBNP therapy applied as treatment during routine schedule may have a systemic effect in lowering serum lactate levels, but not CK levels. Enhanced recovery of athletes is still unconfirmed.

Keywords: lower body negative pressure, athlete restoration, athlete performance, athlete rehabilitation, athlete recuperation

\section{S Afr J Sports Med 2017;29:1-7. DOI: 10.17159/2078-516X/2017/v29i0a1544}

Lower body negative pressure (LBNP) treatment, also known as intermittent vacuum therapy, was developed for astronauts, to maintain the arterial blood supply of the lower body and compensate for weightlessness. Due to the low gravity in space, autonomic cardiovascular control deteriorates and orthostatic tolerance is re-established by means of LBNP therapy after exploration flights. ${ }^{[1]}$

Designed to act as an external heart for the lower body, the LBNP device generates a rhythmic alternating pressure of intermittent waves of negative pressure (lower pressure), and normal pressure (atmospheric pressure). As described in available literature this mechanism causes strong capillary dilation and compression pulsations ${ }^{[2]}$ through which blood circulation and perfusion in the lower limbs are increased..$^{[3]}$ Arteries dilate as oxygen $\left(\mathrm{O}_{2}\right)$-rich blood and nutrients are drawn into the tissue (hypobaric), resulting in a higher available concentration of $\mathrm{O}_{2}$ and supplements in the muscle, ${ }^{[4]}$ followed by an atmospheric pressure phase, a relief of the reflux, when carbon dioxide $\left(\mathrm{CO}_{2}\right)$ and metabolic waste products are pressed back into the upper body through the circulatory system and the lymphatic vessels. ${ }^{[5]}$ This application of sub-atmospheric pressure to the lower portion of the body (below the iliac crest) consequently enhances the baroreflex that assists in maintaining blood pressure during orthostatic stress. ${ }^{[1,2]}$

In clinical applications, the use of negative pressure has been indicated as an effective modality. ${ }^{[4,6]}$ A study by Schneider et al. ${ }^{[7]}$ indicated an improvement in heart rate and blood pressure responses observed with the application of LBNP after 15 days of bed rest.

Following excessive training, athletes often experience symptoms of discomfort, muscular soreness and stiffness within $12-24 \mathrm{~h}$, which can contribute to the development of muscular fatigue resulting in deteriorating performance. ${ }^{[8,9]}$ Delayed onset muscle soreness (DOMS) is an inflammatory reaction caused by the micro-damage of primary muscle. Sports massage is a popular treatment and a frequently applied intervention; however, evidence to support its efficacy as a technique to enhance recovery is still being explored. ${ }^{[10]}$ Appropriate methods of recovery are, however, essential to restore an athlete's physiological and psychological capacities. Prompt and sufficient recovery can also improve performance by enhancing training quality and tolerance to the training load, as well as improving the athlete's adaptation to training. Without proper recovery following multiple training sessions or competitions, an athlete increases the risk for poorer performance and overuse injuries. ${ }^{[8,10]}$ Mimicking sports massage by stimulating the circulatory system and lymphatic vessels, LBNP is claimed to play a vital role in the recovery of the athlete in order to maximise athletic performance in competitive sport.

The endurance capacity in athletes differs, with highly trained athletes performing at a higher maximal oxygen uptake, presenting with minimum lactate accumulation. During exercise of increasing intensity, an increase in blood lactate concentration is an indication of a rise in glycogen metabolism within the muscle. However, the initial increase in blood lactate concentration implies the net result of lactate production in the muscle, and reflects that the appearance rate of lactate in the blood is higher than the disappearance rate (the result of a balance between the rate of production and removal). ${ }^{[11,12]}$ This is referred to as the lactate threshold and is 
considered to be a good predictor of endurance exercise performance. The lactate threshold is often used to prescribe training intensities, based on the relationship between blood lactate levels and heart rate. In the same way, active recovery after strenuous exercise will clear the accumulated blood lactate levels faster than passive recovery. More so in an intensity-dependent manner, with maximum blood lactate clearance occurring with active recovery close to the lactate threshold. ${ }^{[12,13]}$

The severity of muscle damage and injury is frequently monitored by blood serum CK enzyme activity levels. ${ }^{[14]}$ Although debated by researchers, lactate concentration and blood serum CK activity levels are implemented as biomarkers in measuring the recovery process that is crucial for successful endurance capacity and sport performance. ${ }^{[12,13,14]}$

Hormonal changes in the body are involved in regulating various physiological functions, and when activated are known to improve mental function and willpower, thus automatically increasing the subjective well-being of an individual. ${ }^{[15]}$ The increased blood circulation in the entire body and brain achieved by the vacuum effect of the LBNP device may hypothetically also increase oxygen circulation and influence hormone levels and their release in the blood to enhance a feeling of perceived recovery experienced by the athletes, with the magnitude of improvement remaining of a perceptive nature.

LBNP therapy is becoming popular through the promise of an innovative to optimise and accelerate sports recovery, increase physical performance and reduce breaks from training, with very little confirmed evidence. The objective of this study was to assess if intermittent negative pressure therapy applied to the lower body of athletes will affect known measures of muscular recovery and result in faster recovery time and recuperation.

\section{Methods}

\section{Study design}

A randomised cross-over study design with repeated measures was performed to determine the effect negative pressure wave treatment has on the recovery of cricketers. An information letter with a full explanation regarding the nature of the study was given to all participants, and informed written consent forms were collected from each candidate prior to the study. The study protocol was approved by the Ethics Committee of the University of Pretoria, South Africa (Approval number 352/2013).

\section{Participants and selection criteria}

Twenty-two healthy male cricket players based at the TUKS Cricket Academy, at the High Performance Centre of the University of Pretoria, South Africa, were invited to participate. Players were randomly assigned to one of two groups and evaluated. After the second week the participants were crossed over and the study repeated over the following two weeks. Participant exclusion criteria included cardiovascular diseases, hypotony with proneness to collapse, diabetes, recent phlebotrombosis (<eight weeks), the risk of thromboembolism and smoking. Participants were instructed to refrain from drinking alcohol, and consuming caffeine products 24 hours prior to each study session.

\section{Study procedure}

All participants documented their personal information and history before the start of the study. The age, body mass, height and body mass index (BMI) of each athlete were recorded at the start of the study. Each player participated in the cross-over design during the four week study period: once in the treatment group (receiving LBNP treatment; ExT) and once in the control group (not receiving LBNP treatment; ExC). The two applications were separated by a washout period of 14 days. Each trial assessment was completed over three consecutive days and followed the same routine physical, physiological and treatment conduct as illustrated in Figure 1. The cricket players continued to follow their regular weekly physical training programme consisting of seven hours conditioning and 10 hours cricket specific skills, with one competitive match on weekends, throughout the study period.

\section{Protocol}

On the first day of the trial (Figure 1) baseline physiological measurements (heart rate (HR); blood pressure (BP); blood oxygen saturation $\left(\mathrm{SpO}_{2}\right)$ ) and blood samples (Lactate $(\mathrm{Lac})$; Creatine Kinase $(\mathrm{CK})$ ) were collected from the participating athletes pre-exercise. Participants then completed a one hour high-intensity gym session comprising of weighted exercises and plyometric upper and lower limb training. Directly after the exercise session, physiological measurements and blood sample collection were repeated. Players were randomly assigned to either receive one 30 minute LBNP treatment session (ExT) or remain seated in the treatment room with no exposure (ExC). A questionnaire (based on an ordinal rating scale of one to five) was completed by each player before and after every LBNP treatment session, to quantify their perceived recovery state (Table 1). Normal training proceeded in the afternoon and the players returned on Day Two and Day Three during which the same athletes once more received either a treatment session or remained unexposed. Physiological measurements and blood samples were collected daily before and during each treatment session, for both the treatment (ExT) and control (ExC) participants. Treatment sessions were labelled as: 0 hours after, 24 hours after and 48 hours after intense training.

\section{LBNP vacuum therapy}

The LBNP device for intermittent vacuum therapy comprises of a cylinder-shaped chamber into which the lower body of the athlete is placed. The athlete lies on his back, his legs and lower body up to the iliac crest bone, inside the chamber. The chamber, enfolding the lower body of the athlete, is sealed by means of a diaphragm (iris seal) around the waist. Alternating negative and normal pressure is generated in the chamber by a vacuum pump. The device generates rhythmic interchanging pressure waves of normal pressure (atmospheric pressure) and negative pressure (lower pressure) at alternating pulsations. A vacuum treatment with negative pressure setting of 68 mbar was regulated, with an atmospheric pressure:negative pressur 


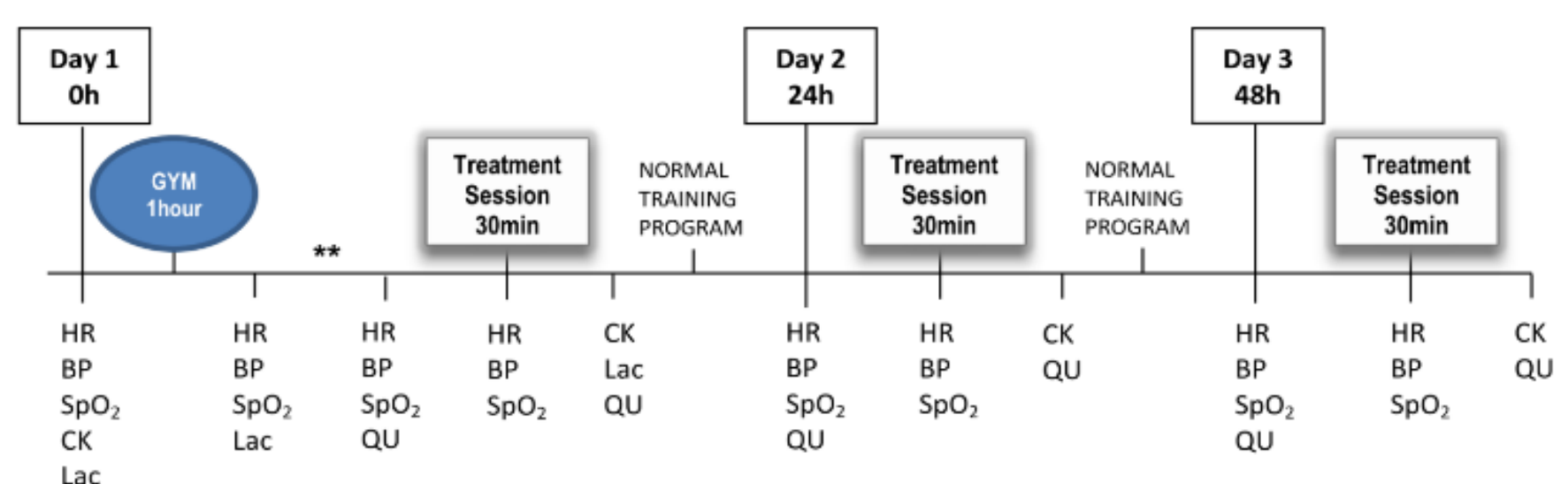

\section{${ }^{\star *}$ Random assignment into ExC/ExT}

Fig.1. Procedure of physiological measurements and blood samples taken over three consecutive trial days. ${ }^{* *}$ Intervention starts. HR, heart rate; $\mathrm{BP}$, blood pressure; $\mathrm{SpO}_{2}$, blood oxygen saturation; $\mathrm{CK}$, creatine kinase; Lac, lactate; QU, questionnaire.

Table 1. Perceived recovery questionnaire

\begin{tabular}{|c|c|c|}
\hline \multirow[t]{2}{*}{ Question } & \multicolumn{2}{|c|}{ Ordinal rating scale } \\
\hline & $1 \longrightarrow$ & $\longrightarrow 5$ \\
\hline Pre-treatment: & & \\
\hline $\begin{array}{l}\text { How does your body } \\
\text { feel after exercise / } \\
\text { before treatment? }\end{array}$ & $\begin{array}{l}\text { Extremely } \\
\text { exhausted }\end{array}$ & $\begin{array}{l}\text { Excellent } \\
\text { condition }\end{array}$ \\
\hline $\begin{array}{l}\text { How do your muscles } \\
\text { feel? }\end{array}$ & Very heavy & $\begin{array}{l}\text { Excellent } \\
\text { condition }\end{array}$ \\
\hline $\begin{array}{l}\text { How does your body } \\
\text { feel in terms of fatigue? }\end{array}$ & $\begin{array}{l}\text { I feel extremely } \\
\text { fatigued }\end{array}$ & $\begin{array}{l}\text { I feel fully } \\
\text { energised }\end{array}$ \\
\hline $\begin{array}{l}\text { Post-treatment: } \\
\text { How do your muscles } \\
\text { feel? }\end{array}$ & Very heavy & $\begin{array}{l}\text { Excellent } \\
\text { condition }\end{array}$ \\
\hline $\begin{array}{l}\text { How does your body } \\
\text { feel in terms of fatigue? }\end{array}$ & $\begin{array}{l}\text { I feel extremely } \\
\text { fatigued }\end{array}$ & $\begin{array}{l}\text { I feel fully } \\
\text { energised }\end{array}$ \\
\hline $\begin{array}{l}\text { How well rested and } \\
\text { regenerated do you feel? }\end{array}$ & Not recovered & $\begin{array}{l}\text { Very well } \\
\text { recovered }\end{array}$ \\
\hline $\begin{array}{l}\text { LBNP effectiveness: } \\
\text { How do you feel after } \\
\text { your treatment session } \\
\text { on the LBNP device? }\end{array}$ & $\begin{array}{l}\text { My body still } \\
\text { feels tired/ } \\
\text { fatigued }\end{array}$ & $\begin{array}{l}\text { My body feels in } \\
\text { great condition }\end{array}$ \\
\hline $\begin{array}{l}\text { Do you have the } \\
\text { impression that the } \\
\text { LBNP device helped? }\end{array}$ & Not impressed & $\begin{array}{l}\text { Extremely } \\
\text { impressed }\end{array}$ \\
\hline
\end{tabular}

Table 2. Baseline physical characteristics of participants ( $\mathrm{N}=22)$

\begin{tabular}{cc}
\hline Table 2. Baseline physical characteristics of participants $(\mathbf{N}=\mathbf{2 2})$ \\
\hline Variables & Mean \pm SD \\
\hline Age (years) & $20 \pm 1$ \\
Body weight $(\mathrm{kg})$ & $79.6 \pm 8.2$ \\
Height $(\mathrm{cm})$ & $180.0 \pm 0.1$ \\
BMI $\left(\mathrm{kg} / \mathrm{m}^{2}\right)$ & $24.6 \pm 2.5$ \\
\hline
\end{tabular}

alternating phase duration of 9:6 seconds. The LBNP device used during this study period was voluntarily supplied by Rapid Sports Medical Regeneration, South Africa.

\section{Physiological measurements}

Vital health assessments - heart rate (HR), blood pressure (BP) and blood oxygen saturation $\left(\mathrm{SpO}_{2}\right)$ - were noted throughout the study, for both the ExT and the ExC athletes. $\mathrm{SpO}_{2}$ (oxyhaemoglobin and deoxy-haemoglobin in the red blood cells) was monitored using a Finger Pulse Oximeter Probe (Anapulse ANP150).

\section{Blood lactate concentration}

A small blood sample $(0.3 \mu \mathrm{l})$ was collected by means of a lancet prick of the earlobe to determine the blood lactate concentration (mmol/l) of all athletes (both the ExT group and the ExC group). Analysis was performed using Lactate $\mathrm{Pro}^{\mathrm{TM}} 2$ test strips (Batch\# B133B03L) and a portable blood lactate analyser (Arkray Pro2 LT-1730). Lactate was sampled at rest on Day One (Lac0), immediately after the one hour exercise session (Lac1) and directly after the first $30 \mathrm{~min}$ LBNP treatment session (Lac2).

\section{Serum creatine kinase enzyme activity levels (CK)}

CK levels (IU/litre enzyme activity) were assessed from approximately five $\mathrm{ml}$ of blood drawn from an antecubital vein by venipuncture. Blood samples were obtained at baseline and at 0 hours, 24 hours and 48 hours respectively after treatment and were analysed (Creatine Phosphokinase Assay; Beckman UniCel ${ }^{\circledR}$ DxC800 Synchron) to determine possible increases in CK blood serum levels.

\section{Perceived recovery questionnaire}

The questionnaire was based on an ordinal rating scale of one to five, to evaluate the perceived amount of recovery with LBNP therapy (of all athletes: ExC and ExT). The questions were designed to explore the subjective perceptions of their intensity of muscle soreness and their level of recovery, comparing pre-treatment and post-treatment on the LBNP device (Table 1). Athletes belonging to the ExT group were also questioned on their opinion of the effectiveness of LBNP therapy.

\section{Data analysis}

The data analysis consisted of descriptive statistics to 
summarise the quantitative information. Repeated measures ANOVA was used to assess the changes in blood lactate concentration and CK activity levels over the 48 hour treatment period between the treatment and control groups. The proportional changes (after vs. before) of the treatment were evaluated and interpreted as follows: values smaller than one indicate a decrease, values larger than one an increase and a value of one would indicate no change took place.

The results of the perceived recovery questionnaire were combined into pre-treatment recovery scores and posttreatment recovery scores. Non-parametric Mann-Whitney U tests were performed to determine differences between the treatment and control groups for each of the three periods. The results were regarded as significant if $p<0.05$, one-tailed.

\section{Results}

The baseline physical characteristics of the participants at the start of the study are reported in Table 2. Figure 2 shows the systolic and diastolic BP for both the ExT and the ExC athletes. The negative pressure generated by the LBNP device on BP can clearly be seen in the systolic and diastolic fluctuations during the treatment sessions. Although there were slight changes in the $\mathrm{HR}$ and $\mathrm{SpO}_{2}$ measurements before and during each treatment session in the ExT and ExC groups, there were no significant differences in these physiological measurements; these differences are due to sample variation.

Figure 3 illustrates the results of the blood lactate concentration $(\mathrm{mmol} / \mathrm{l})$ on Day One at baseline (Lac0), after a one hour (Lac1) intense exercise session, and after the first 30 minute (Lac2) LBNP therapy session. The average blood lactate concentration ( $\mathrm{mmol} / \mathrm{l}$ ) ratio (after vs. before) of the ExT group decreased after treatment, in comparison to the ExC group who did not receive treatment $(0.57 \pm 0.23$ vs. $0.78 \pm 0.22$, respectively, $F(1 ; 19)=9.420, p=0.006)$. No other significant differences were obtained.

The CK measurements for both groups are shown in Figure 4. Although there was an increase in CK enzyme activity following the first day's training, the CK did not decrease significantly after three treatment sessions on the LBNP device $(\mathrm{F}(1 ; 19)=0.172 ; \mathrm{p}=0.683)$.

Figure 5 shows the perceived recovery grading of both ExC and ExT athletes over a three day period during pre-treatment and post-treatment on the LBNP device (based on the questions in Table 1). The three pre-treatment questions were combined to get a pre-treatment recovery score, and the three posttreatment questions were combined to get a post-treatment recovery score. There was a significant difference between the ExC and ExT groups (post-treatment score minus pre-treatment score) at all three time periods $(0 \mathrm{~h} p=0.011 ; 24 \mathrm{~h} p<0.001 ; 48 \mathrm{~h}$ $\mathrm{p}=0.001$ ). At post-treatment, after each of the 0 hour, 24 hour and 48 hour sessions, the ExT athletes reported a significant increase in their perceived degree of muscle feel, fatigue and recovery compared to the controls. The ExT group during each of the treatment periods indicated higher energy and recovery status than the ExC group.

\section{Discussion}

The decrease in the blood lactate concentration ratio of the treatment group compared to the control group $(0.57 \pm 0.23$ vs. $0.78 \pm 0.22 \mathrm{mmol} / \mathrm{l}$, respectively, $\mathrm{p}<0.001)$, following a single negative pressure treatment session, indicates that the use of the LBNP device succeeded in normalising lactate measurements more quickly, and may imply faster athlete rehabilitation and recovery. Per contra, the severity of muscle injury as indicated by the blood serum CK level of activity was not significantly reduced after three treatment sessions of negative pressure $(F(1 ; 19)=0.172 ; p=0.683)$.

Negative vacuum pressure treatment did not affect the ongoing sports performance of the athletes, and no side effects were observed during the period the study was executed. All participants also form part of the same cricket academy and therefore their training schedules are fairly similar.

Several physiological systems change when endurance training is induced (i.e. metabolic, cardiovascular, muscular, etc.), with the modification of lactate kinetic parameters a significant mediator to quantify the extent of exercise. ${ }^{[12]}$ The mean blood lactate ratio between the control (ExC) and treatment (ExT) groups, directly after exercise vs. directly

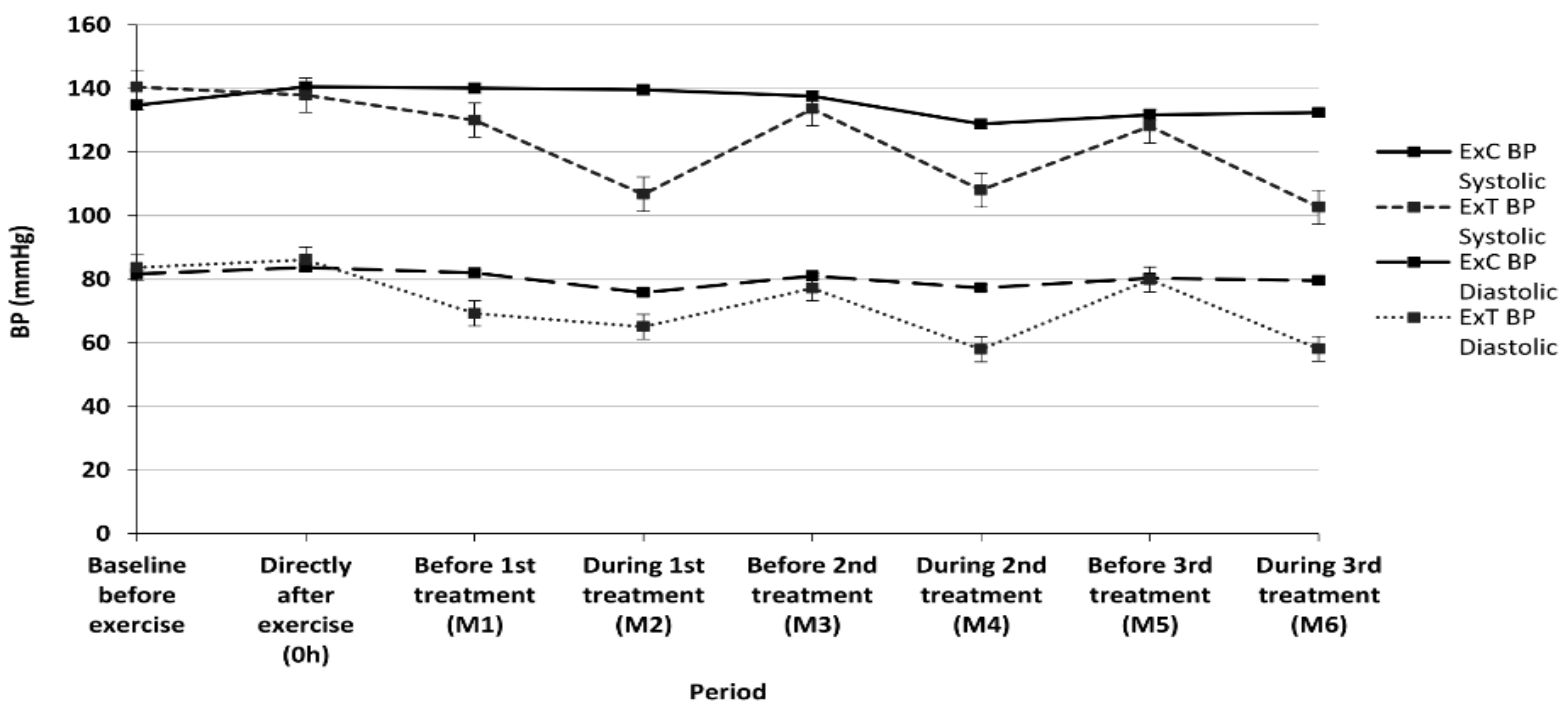

Fig.2. Systolic and diastolic blood pressure $(N=22)$. M, Measurement. 


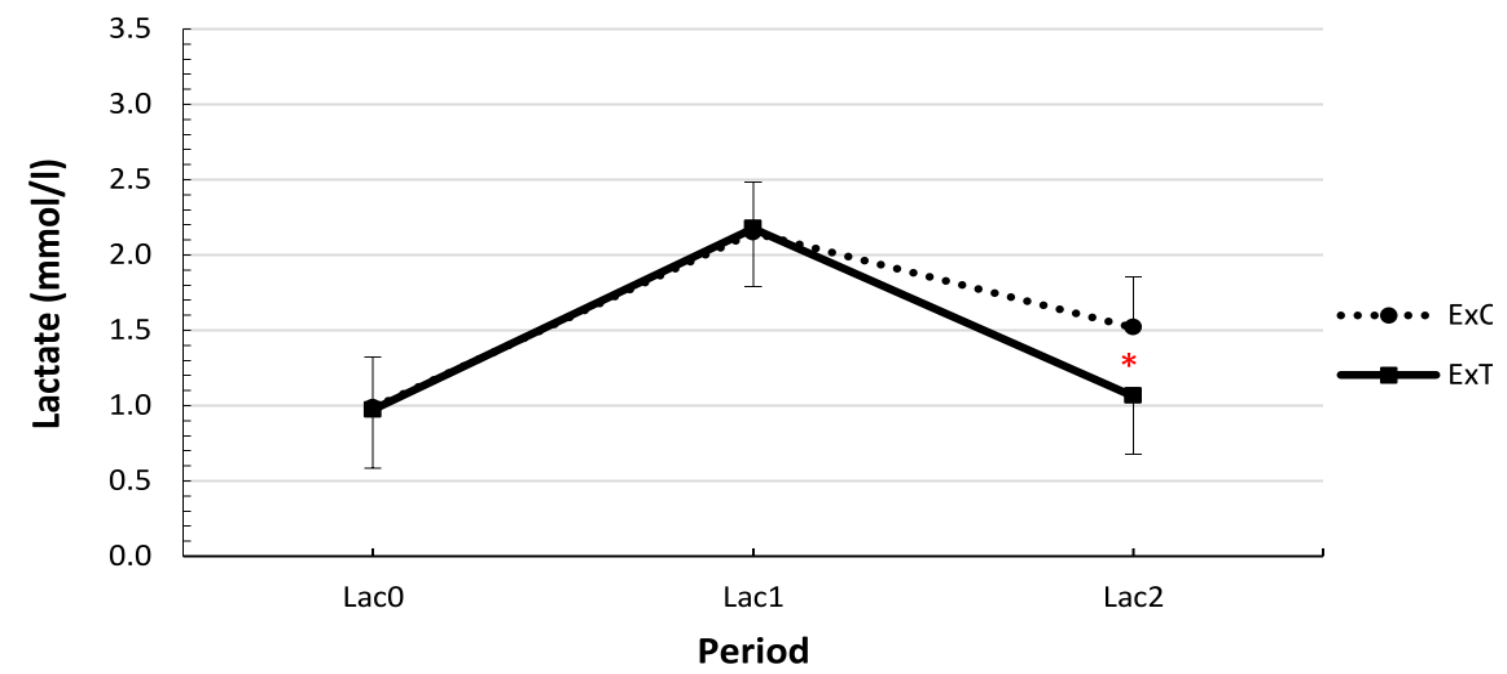

Fig.3. Mean blood lactate concentration (mmol/l) on Day One at baseline (Lac0), after one hour of exercise (Lac1), and after 30 minutes therapy (Lac2) on the LBNP device (N=22). * Ratio significant at $\alpha<0.01$.

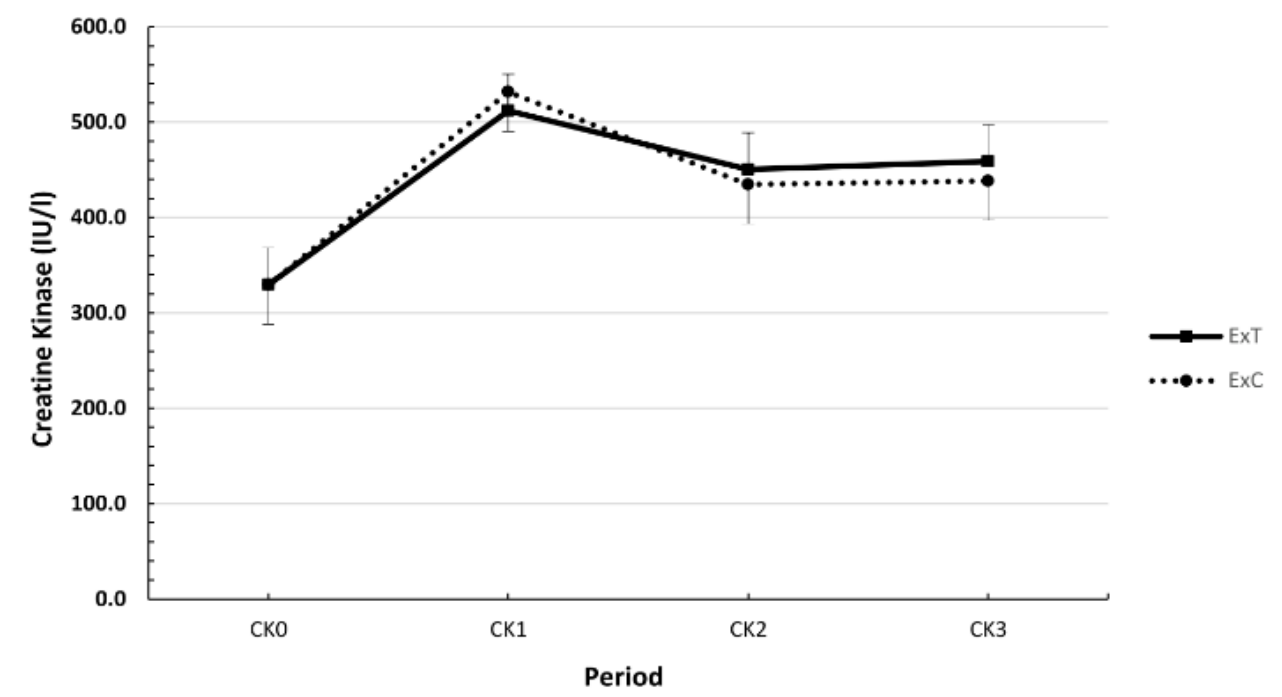

Fig.4. Mean creatine kinase enzyme activity on Day One at baseline (CK0), after one hour of exercise and the 1st therapy session (CK1), after the $2^{\text {nd }}$ therapy session $(C K 2)$, and after the $3^{\text {rd }}$ therapy session $(C K 3)(N=22)$. No significant decrease was found.

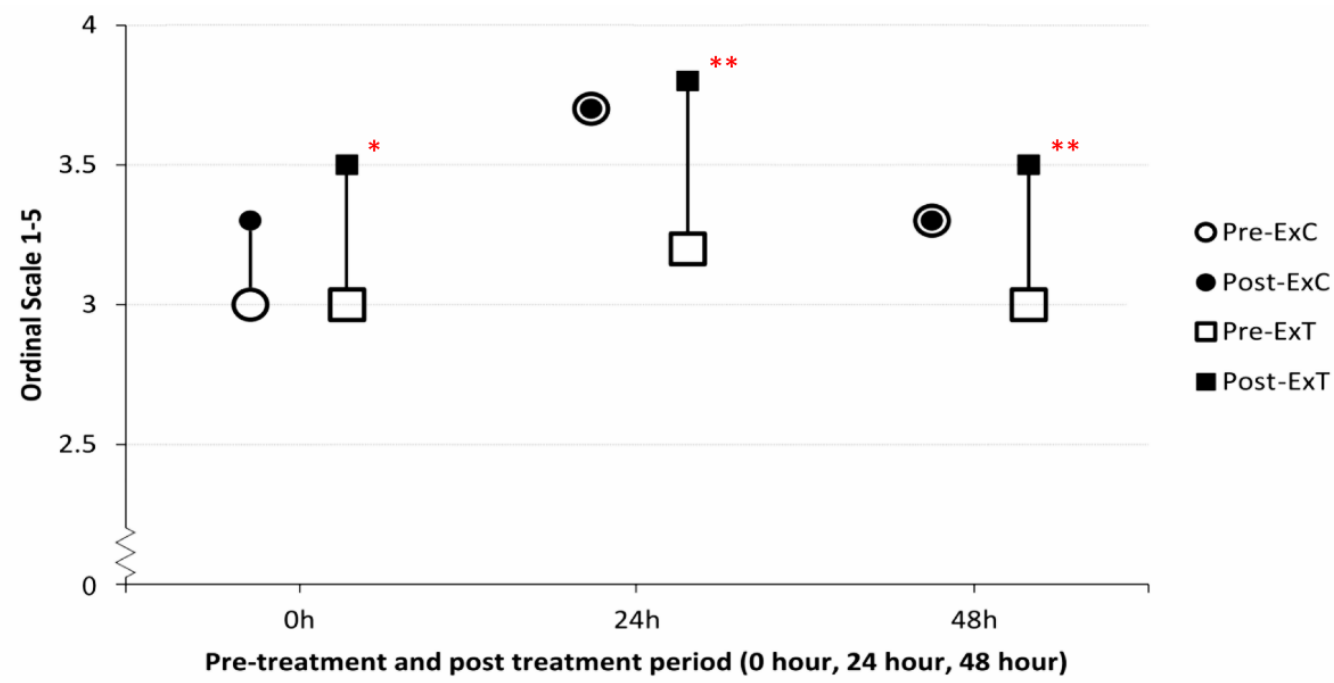

Fig.5. Perceived recovery based on an ordinal scale indicating the post-treatment recovery score minus pre-treatment recovery score responses of both ExC and ExT athletes groups on the LBNP device, for the 0 hour, 24 hour and 48 hour sessions. Ordinal scale relates to questions AF in Table 1. ${ }^{*}$ Significant at $5 \%$ level; ** Significant at $1 \%$ level. 
after the $1^{\text {st }}$ treatment session, demonstrated a significantly faster decrease in the treatment group, indicating the efficiency of the LBNP device to stimulate blood flow and as an aid in the removal of lactate.

However, the daily academy training and competition programme the athletes followed, although fairly similar, may also have influenced the $\mathrm{CK}$ serum results. Again, the objective of evaluating negative pressure effect on recovery under acute athlete performance conditions is highlighted in this study.

The stimulation of the circulatory system and the lymphatic vessels by the rhythmic alternating pressure of the LBNP device may conceivably mimic massage therapy. Sports massage is used by athletes with the belief that it will stimulate lymph flow and reduce muscle tightness in order to accelerate recovery and enhance performance. Improvement in muscle tone and a sense of feeling recovered and energised by the increased concentration of endorphins in the brain has also been advocated. Although many claimed benefits and numerous personal perceived experiences promote sports massage as the treatment of choice, research evidence on its appropriate use is scarce ${ }^{[10]}$ with contradictory evidence that manual massage has any significant impact on the physiological and psychological factors associated with recovery following exercise. ${ }^{[9,10]}$

Recovery may be reliably assessed both at pre- and posttreatment with one-dimensional tools, such as individual evaluated numeric rating scales. Athletes who were treated with the LBNP device during their routine weekly training programme reported an increased subjective impression of treatment compared to that of the control athletes. A perceived improvement in muscle feeling and fatigue was seen, and they experienced increased training motivation and an enhanced feeling of recovery in general. The athletes described the treatments as 'pleasant' and rated their treatment sessions on the LBNP device as highly effective, reflecting the impression that the treatment sessions may help them to recover more quickly. At posttreatment, after each of the 0 hour, 24 hour and 48 hour sessions, the ExT athletes reported a significant increase in their perceived degree of muscle feel, fatigue and recovery compared to the controls. The ExT group, during each of the treatment periods, indicated a higher energy and recovery status than the ExC group. The perceived perceptions of recovery that increased after each vacuum therapy session provides some support for the use of the LBNP device as a recovery strategy to improve the recovery state of the athlete. It has to be noted that the project specifically targeted short-term acute recovery and does not reflect on how the use of the LBNP device will be perceived over the long-term. The performance, motivation and subjective wellbeing of the athlete may well be further enhanced with the continuous use of the device.

A limitation to this study is the short period the LBNP treatment was implemented, but the core emphasis was to determine acute athlete rehabilitation and recovery based on known measures of muscular recovery within a short period of time after high-intensity exercise. Beneficial to the device itself will be a further examination of its effectiveness and significance based on performance enhancement, recovery and rehabilitation of athletes, and the advanced development of various treatment programmes.

\section{Conclusion}

Based on this study, LBNP therapy implemented as an applied treatment within cricket players' normal routine training and competition schedule, in an effort to assist in the recovery of players over a short period of time, seems to have a systemic effect in lowering serum lactate levels, but not CK levels. The enhanced long-term recovery of athletes using this device to replenish faster and recuperate more efficiently as advocated, are still unconfirmed.

Acknowledgements: The authors are grateful to Gustav Obermeyer of Rapid Sports Medical Regeneration (RSMR), South Africa who voluntarily supplied the Vacumed ${ }^{\circledR}$ (LBNP device) for the research performed at the University of Pretoria, South Africa.

Conflicts of interest: There are no conflicts of interest related to this study.

Source of funding: The authors declare that they have not received any funding for this study.

Statement: The protocol was approved by the Ethics Committee of the University of Pretoria, South Africa (Approval number 352-2013). Experiments comply with the current laws of South Africa in which they were performed.

\section{References}

1. Baisch F, Beck L, Blomqvist G, et al. Cardiovascular response to lower body negative pressure stimulation before, during, and after space flight. Eur J Clin Invest 2000;30(12):1055-1065. [http://dx.doi.org/10.1046/j.1365-2362.2000.00750.x]

2. Cooper VL, Hainsworth R. Carotid baroreceptor reflexes in humans during orthostatic stress. Exp Physiol 2001;86(5):677681. [http://dx.doi.org/10.1113/eph8602213]

3. Hisdal J, Toska K, Flatebø T, et al. Onset of mild lower body negative pressure induces transient change in mean arterial pressure in humans. Eur J Appl Physiol 2002;87(3):251-256. [http://dx.doi.org/10.1007/s00421-002-0630-4]

4. Stannard JP, Singanamala N, Volgas DA. Fix and flap in the era of vacuum suction devices: What do we know in terms of evidence based medicine? Injury 2010;41(8):780-786. [http://dx.doi.org/10.1016/j.injury.2009.08.011]

5. Hachiya T, Blaber AP, Saito M. Changes in superficial blood distribution in thigh muscle during LBNP assessed by NIRS. Aviat Space Environ Med 2004;75(2):118-122. [http://www.ingentaconnect.com/content/asma/asem/2004/00 000075/00000002/art00004]

6. Krug E, Berg L, Lee C, et al. Evidence-based recommendations for the use of Negative Pressure Wound Therapy in traumatic wounds and reconstructive surgery: Steps towards an international consensus. Injury 2011;42 Suppl.1:S1-S12. [http://dx.doi.org/10.1016/S0020-1383(11)00041-6]

7. Schneider SM, Watenpaugh DE, Lee SM, et al. Lower-body 
negative-pressure exercise and bed-rest-mediated orthostatic intolerance. Med Sci Sports Exerc 2002;34(9):1446-1453. [http://dx.doi.org/10.1097/00005768-200209000-00008]

8. Torres R, Ribeiro F, Alberto Duarte J, et al. Evidence of the physiotherapeutic interventions used currently after exercise-induced muscle damage: Systematic review and meta-analysis. Phys Ther Sport 2012;13(2):101-114. [http://dx.doi.org/10.1016/j.ptsp.2011.07.005]

9. Hemmings B, Smith M, Graydon J, et al. Effects of massage on physiological restoration, perceived recovery, and repeated sports performance. Br J Sports Med 2000;34(2):109114. [http://dx.doi.org/10.1136/bjsm.34.2.109]

10. Brummitt $\mathrm{J}$. The role of massage in sports performance and rehabilitation: current evidence and future direction. N Am J Sports Phys Ther 2008;3(1):7-21. [http://www.ncbi.nlm.nih.gov/pmc/journals/1328/] [PMCID: PMC2953308]

11. Brooks GA. The lactate shuttle during exercise and recovery. Med Sci Sports Exerc 1986;18(3):360-368. [http://dx.doi.org/10.1249/00005768-198606000-00019] [PMID:3523107]
12. Gharbi A, Chamari K, Kallel A, et al. Lactate kinetics after intermittent and continuous exercise training. J Sports Sci Med 2008;7(2):279-285. [http://www.jssm.org/researchjssm-07279.xml.xml] [PMCID: PMC3761459]

13. Menzies P, Menzies C, McIntyre L, et al. Blood lactate clearance during active recovery after an intense running bout depends on the intensity of the active recovery. J Sports Sci 2010;28(9):975-982.

[http://dx.DOI.org/10.1080/02640414.2010.481721]

14. Baird MF, Graham SM, Baker JS, et al. Creatine-kinase- and exercise-related muscle damage implications for muscle performance and recovery. J Nutr Metab 2012;2012: 960363. [http://dx.doi.org/10.1155/2012/960363]

15. Gasiorowska A, Mikulski T, Smorawiński J, et al. Cardiovascular and neurohormonal responses to lower body negative pressure (LBNP): effect of training and 3 day bed rest. J Physiol Pharmacol 2006;57 Suppl.10:85-100. [http://jpp.krakow.pl/journal/archive/11_06_s10/articles/07_art icle.html] 